\title{
Slovak Level Crossings - Present State and Knowledge-Based Approach to Diagnostics
}

\author{
Aleš Janota* and Jana Šebeňová*
}

\author{
University of Žilina, Faculty of Electrical Engineering, Department of Control an Information Systems, Slovakia
}

\begin{abstract}
This paper consists of tree principal parts. The first part discusses the problem of safety of Slovak level crossings, seen through the statistic data, and explains distinctive features identified on the base of comparison with level crossings operated in other EU countries. The second part deals with knowledge-based approach applied to diagnostics of electronic/computer-based level crossing installations. In the last part the authors present their methodology which has been designed and which is to be applied to the level crossing systems of a particular producer and describe possible architectures of such a system.
\end{abstract}

Keywords: Level crossing, diagnostics, knowledge-based approach, safety, statistics.

\section{INTRODUCTION}

The introduction characterizes conditions under which railway level crossings are operated in the Slovak Republic. The part 1.1 gives basic statistic data and explains national terminology and specificities. The part 1.2 deals with analysis of accident rates and future trends. The part 1.3 explains some of Slovak specificities.

\subsection{Introduction: Present Situation}

The Slovak Republic covers an area of $48800 \mathrm{~km}^{2}$ and has 5401 million inhabitants [1]. Length of the road network is $328 \mathrm{~km}$ of motorways, $3359 \mathrm{~km}$ of main or national roads, $14141 \mathrm{~km}$ of secondary or regional roads and 25942 of other roads (figures from the end of 2006, according to [1]). In 2007 there were 627 road fatalities in that network. As far as the railway infrastructure is concerned, construction length of managed railway lines was $3629 \mathrm{~km}$ in 2007 and $3623 \mathrm{~km}$ in 2008. Numbers of railway level crossings were 2307 in 2007 and 2265 in 2008. They can be classified according to different classification (in some countries also called "categorization") schemes. Comparison of different types of LC systems requires harmonization of classification and using "the same language" from country to country. Appropriate solution seems to be adoption of the recommended ERA-based classification of LC types as shown in Fig. (1). This classification distinguishes between active (group A) and passive (group B) level crossings. The passive type of the LC may be any LC equipped with any warning signs, plates, devices or any other protection equipment, whose state is permanent and totally not dependent on any traffic situation. The active types of LCs react somehow by changing their states (warning and/or protection). Importance of this basic classification comes in sight when one starts to group different national LC types to common classes. Here too there is a threat of misunder-

*Address correspondence to these authors at the KRIS EF ŽU, Univerzitná 1, SK-01026 Žilina, Slovak Republic; Tel: +421-41-5133356, 5132066; Fax: +421-41-5131515;

E-mails: jana.sebenova@fel.uniza.sk, ales.janota@fel.uniza.sk standing due to different meanings and different terminology used on the national level. One or two examples can be given using example of Slovak LCs type categorization included in the Table 1. For example, the meaning of Slovak category "unprotected" publicly used in [2] is different from "unprotected" (or "non-protected") used in ERA classification. The former case means all LCs equipped only with St. Andrew's Cross while in the latter case there is absolutely no equipment installed at the railway level crossing (neither passive St. Andrew's Cross). To understand the Slovak national terminology which is partially different from those used in other countries, see the cross-reference Table 1. The ERA-based classification was adopted e.g. by the SELCAT project consortium [3].

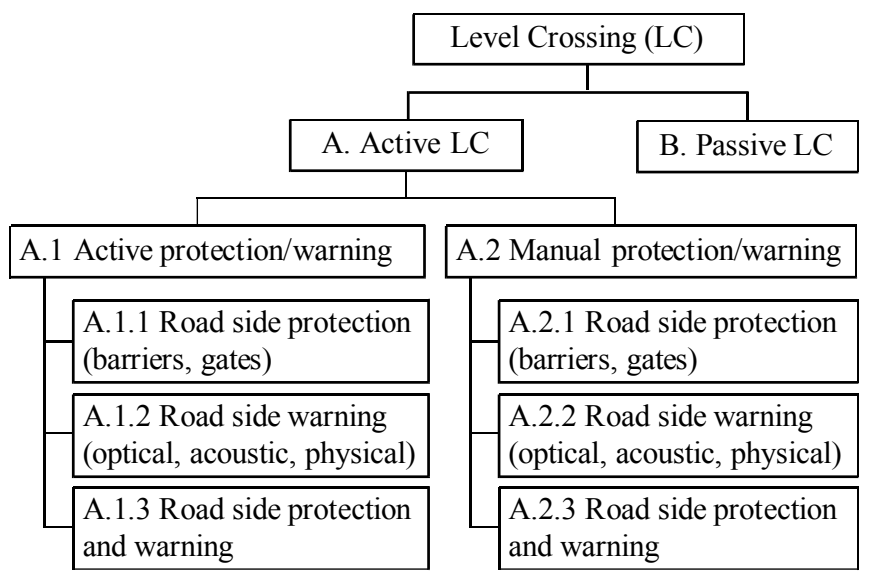

Fig. (1). Recommended ERA classification of LC types.

The more detailed look at the national figures can be found in Table 2 [2].

It should be noted that each Slovak LC type may cover different technical systems (products) coming from different producers but having certain common properties.

\subsection{Introduction: Analysis of Accident Statistics}

Generally, railway infrastructure operators in European countries use their own approaches to collect LC statistic 
Table 1. Correspondence Between Slovak LC Types and ERA Classification

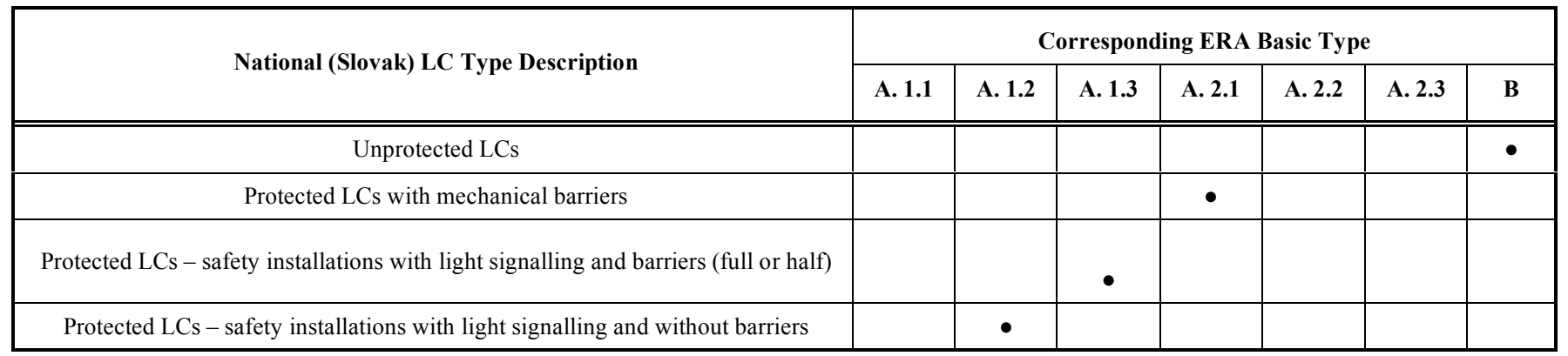

Legend: • The national LC type corresponds to the particular ERA basic type.

data. As an example, Fig. (2) shows a part of a typical accident statistic report as recorded in Slovakia. In the case shown below accident events are classified to several categories (classes) according to the valid Slovak regulation [4]. This classification is based on three categories, each of them having further sub-classification:

- $\quad A-$ Great Accidents: accident events with at least 1 serious consequence such as fatality, serious injury, 7 or more persons lightly injured, serious damage (totally 5 sub-categories);

- $\quad B$-Medium Accidents: accident events where max 6 persons were injured and/or large damage caused (totally 5 sub-categories); and

- $\quad C$ - Safety Threats: accident events having only potential, not real consequences (totally 16 subcategories).

Data shown in Table 3 indicates that automatic LCs without barriers are approximately twice dangerous than LCs with barriers. More detailed analysis (not presented here) proves approximately half number of accidents for full- than half-barriers. Barriers represent a physical obstacle that can be less unseen than light signalling and non-respecting it usually requires more complicated manoeuvre of a road traffic participant. Low number of accidents at active LCs manually operated can be seen as a certain paradox if considering traditionally high failure rate of a human factor. However, this kind of the LC is systematically removed and substituted with automatic technologies.

Table 2. Detailed Classification of the Slovak LCs

\begin{tabular}{|c|c|c|}
\hline Level Crossing Safety Installations & $\mathbf{2 0 0 7}$ & $\mathbf{2 0 0 8}$ \\
\hline \hline Passive level crossings & 1222 & 1163 \\
\hline Active level crossings, out of which & 1085 & 1102 \\
\hline - manual protection/warning ** & 123 & 103 \\
\hline **Including of 13 permanently locked. & 962 & 999 \\
\hline
\end{tabular}

Data in Table 4 shows numbers of fatalities distributed over different kinds of LCs together with total numbers of fatalities in road transport (again for the period 1995-2006). Fatalities at railway LCs represent ca $2 \%$ of all fatalities in road transport. This relatively low percentage causes that road infrastructure managers pay less attention to LC safety equipment (expressed e.g. by financial investments to LC installations). However, at the same time, performed analysis proves that overwhelming majority of accidents has been caused by inadequate behaviour of road traffic participants (see Table 5).

Table 3. Numbers of Accidents at Slovak LCs [6]

\begin{tabular}{|c|c|c|c|c|c|}
\hline & Passive LCs & Active (Mechanical) LCs & Automatic LCs without Barriers & Automatic LCs with Barriers & LCs Total \\
\hline 1995 & 26 & 5 & 24 & 12 & 67 \\
\hline 1996 & 40 & 3 & 29 & 9 & 81 \\
\hline 1997 & 38 & 2 & 30 & 11 & 81 \\
\hline 1998 & 43 & 5 & 27 & 27 & 102 \\
\hline 1999 & 34 & 1 & 30 & 12 & 77 \\
\hline 2000 & 35 & 0 & 47 & 2 & 84 \\
\hline 2001 & 30 & 0 & 20 & 17 & 67 \\
\hline 2002 & 32 & 0 & 30 & 13 & 75 \\
\hline 2003 & 17 & 0 & 14 & 9 & 40 \\
\hline 2004 & 27 & 0 & 26 & 6 & 59 \\
\hline 2005 & 35 & 1 & 27 & 8 & 71 \\
\hline 2006 & 22 & 0 & 33 & 3 & 58 \\
\hline
\end{tabular}


Table 4. Numbers of Fatalities at Slovak Railway LCs and Roads [6]

\begin{tabular}{|c|c|c|c|c|c|c|}
\hline & Unprotected LCs & $\begin{array}{l}\text { Manual (Mechanical) } \\
\text { LC Systems }\end{array}$ & $\begin{array}{c}\text { Automatic LC Systems - } \\
\text { without Barriers }\end{array}$ & $\begin{array}{c}\text { Automatic LC Systems - } \\
\text { with Barriers }\end{array}$ & LCs Totally & Roads Totally *** \\
\hline 1995 & 0 & 0 & 3 & 0 & 3 & 660 \\
\hline 1996 & 4 & 0 & 4 & 0 & 8 & 616 \\
\hline 1997 & 2 & 0 & 8 & 4 & 14 & 788 \\
\hline 1998 & 3 & 0 & 8 & 1 & 12 & 819 \\
\hline 1999 & 3 & 0 & 5 & 0 & 8 & 647 \\
\hline 2000 & 5 & 0 & 3 & 1 & 9 & 628 \\
\hline 2001 & 4 & 0 & 6 & 3 & 13 & 614 \\
\hline 2002 & 6 & 0 & 8 & 0 & 14 & 610 \\
\hline 2003 & 1 & 0 & 4 & 0 & 5 & 645 \\
\hline 2004 & 7 & 0 & 1 & 2 & 10 & 603 \\
\hline 2005 & 3 & 0 & 3 & 1 & 7 & 560 \\
\hline 2006 & 1 & 0 & 7 & 4 & 12 & 579 \\
\hline
\end{tabular}

** CARE project data.

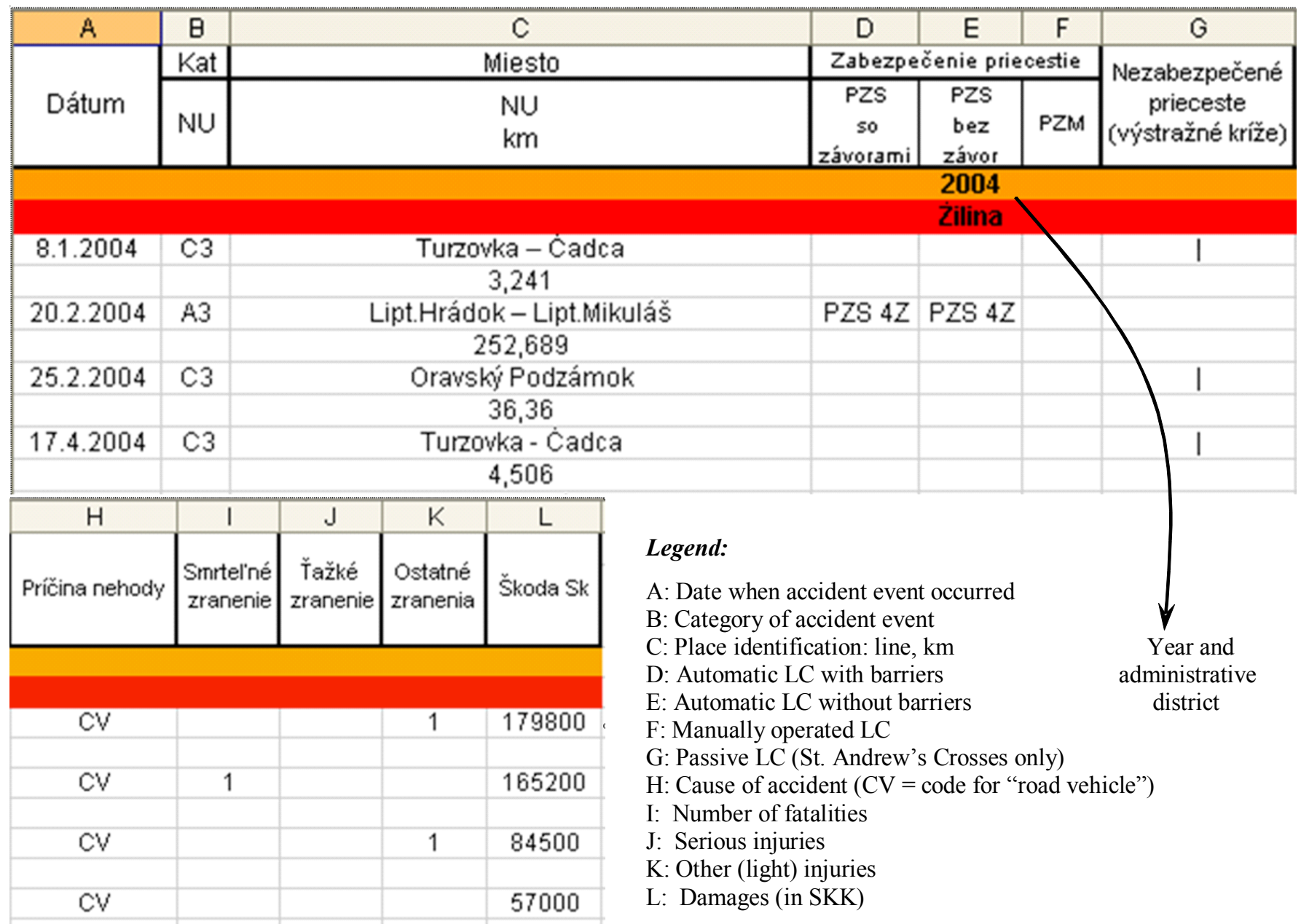

Fig. (2). Sample of a typical record from the Slovak accdent record database. 
Table 5. Analysis of Accidents at LCs Equipped with Automatic LC Systems

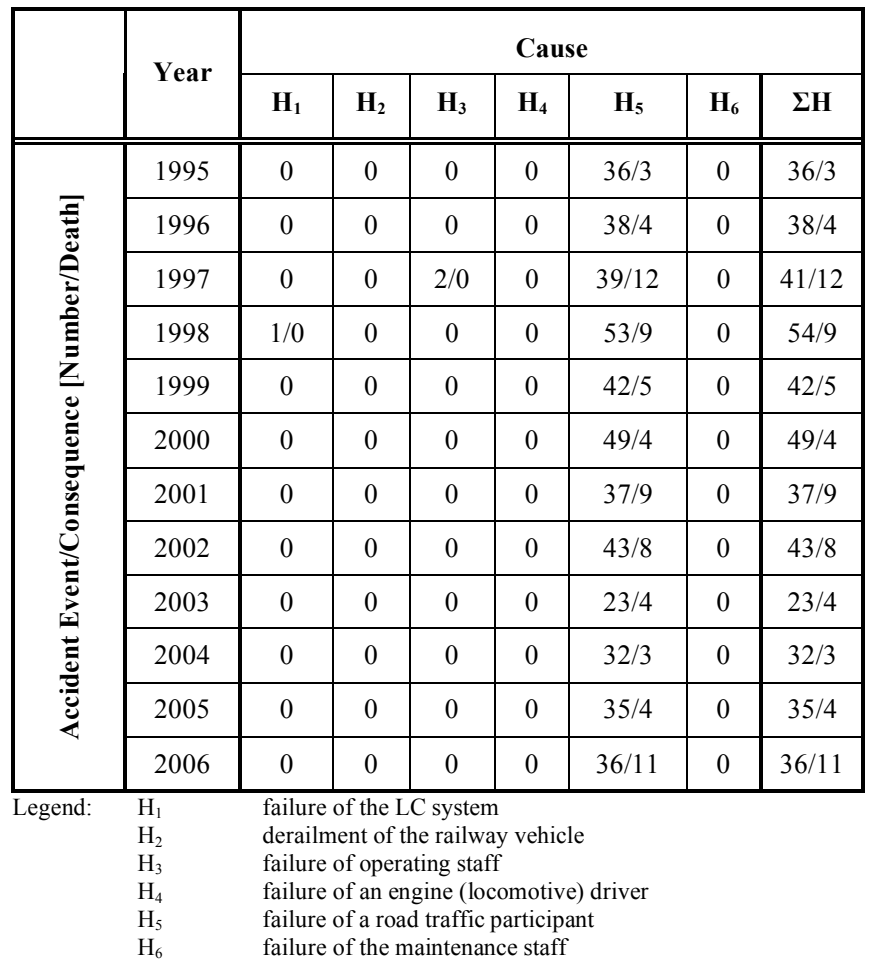

Generally, there is a problem to make comparison of raw data contained in different accidents statistics available from different countries. LC safety performance monitoring is a permanent activity that includes collecting of all accident and serious injury data, evaluation, analysis of accidents and incidents causes and reporting, collaboration with road representative organisations, research and implementation results. Comparability of accident LC statistics encounters differences existing in evaluating LC safety performance in particular countries. For example, there are different definitions for accidents/ incidents and/or serious injuries (this is harmonized by ERA as interpretation of Safety Directive). Not all of railways use the term "serious injury" (e.g. Japan) or "light injury" (e.g. Finland, Japan, Morocco, and Russia). Incidents (near misses) are usually not included into the statistics or incident reports do not exist. This situation could be improved by usage of common safety indicators proposed by the ERA.

Another problem is inconsistency of available statistical data. Different approaches are applied if the problem of suicide statistics is discussed (should be involved or ignored?). What's more the raw statistics for the number of LC accidents are not sufficient since they do not consider existing differences among countries. Therefore, they must be normalized - divided by a proper normalization (scaling) factor reflecting existing differences in the population of the country, number of train movements, number of passengers etc.

Generally, the normalized statistic value usable for comparison is given by the equation (1):
$N_{\text {LCAnormalized }}=\frac{N_{L C A}}{n f}$,

where $N_{L C A}$ is the absolute statistic value (e.g. a number of level crossing accidents) and $n f$ is the normalization factor. Simple normalization factors (such as population, population density, length of railway network exclusive high speed lines, number of cars per 1000 inhabitants, number of railway or road accidents etc.) are suitable when the comparison of accident statistics should reflect only a single country. Composite normalization factors are needed for the cases of international comparisons. They should respect both railway and road influence. More detailed information about comparison of LC accident data can be found in [10].

Special attention also has to be paid to the legislative framework for LC management and operation (general and traffic national laws, standards, guidelines), overview of relevant speeds, times and rates defined by the law and responsibilities for LC accidents. No significant and essential differences have been identified in partner countries; however there are certain aspects requiring future harmonization. Operational rules should be harmonized the first together with responsibilities of all involved subjects (railway infrastructure, railway undertaking, road authority, road user) due to existing differences. Harmonization of the signing will be very costly in the near future since there are a large number of different installations (the Vienna convention on Road Signs and Signals from November $8^{\text {th }}$, 1968 has been still the only legislative document dealing with standardising of road traffic signs on railway level crossing).

\subsection{Introduction: Slovak Particularities}

The warning state at Slovak LCs (warning given towards road traffic participants) is represented by two alternatively flashing red lights placed horizontally side by side, often supplemented with some kind of audio warning. A typical Slovak particularity is usage of so called "active signalling" which is a special kind of signal given by one flashing white light. The meaning of this signal is "there is no railway vehicle coming that could endanger road traffic participants crossing a dangerous zone". The original idea of this signal implementation was to indicate that in special cases the railway infrastructure manager takes responsibility for safety at the LC. Despite the fact that this interpretation was later abandoned many car drivers still believes in its validity. Usage of this signal is regulated by the technical standard [7]. However, for unfamiliar users (especially those coming from abroad) this kind of signalling may be a little bit strange and/or ambiguous, since not all LCs are equipped with this signal, and if they are - sometimes the white light is flashing, sometimes is off, depending on operation state of the level crossing.

Another particularity is that under no circumstances a road driver is exempted from liability for safe crossing the rails. The law [8] says that if white light is flashing ("active signalling" is on) a driver is obliged to respect the speed limit $50 \mathrm{~km}$ per hour when being $50 \mathrm{~m}$ or less to the level crossing. Otherwise, the maximum allowed speed is $30 \mathrm{~km}$ per hour. 
LCs are operated at the lines with the maximum line speed $120 \mathrm{~km}$ per hour. In recent years the main corridor lines have been reconstructed to the maximum speed $160 \mathrm{~km}$ per hour, in several parts $200 \mathrm{~km}$ per hour. LCs situated at corridor lines are systematically removed and substituted with fly-over crossings.

Looking at technology level, the Slovak Railways (ŽSR) operate mostly relay-based LC safety systems realised on the principle of inherent fail-safety (types AŽD, ZSSR, VÚD,...). Electronic LC safety systems based on the principle of composite fail-safety (ELEKSA by Siemens; PZZ-AC by AŽD Prague and SPA 4 by Bombardier) are operated still on a small scale (ca $3 \%$ ).

\section{KNOWLEDGE-BASED DIAGNOSTICS}

Fig. (3) shows principal decomposition of LC functions as adopted in the SELCAT project. Electronic and computerbased technologies, whose safety is based on composite failsafety principle, may utilise a wide range of possible diagnostic approaches to identify potential LC failure state.
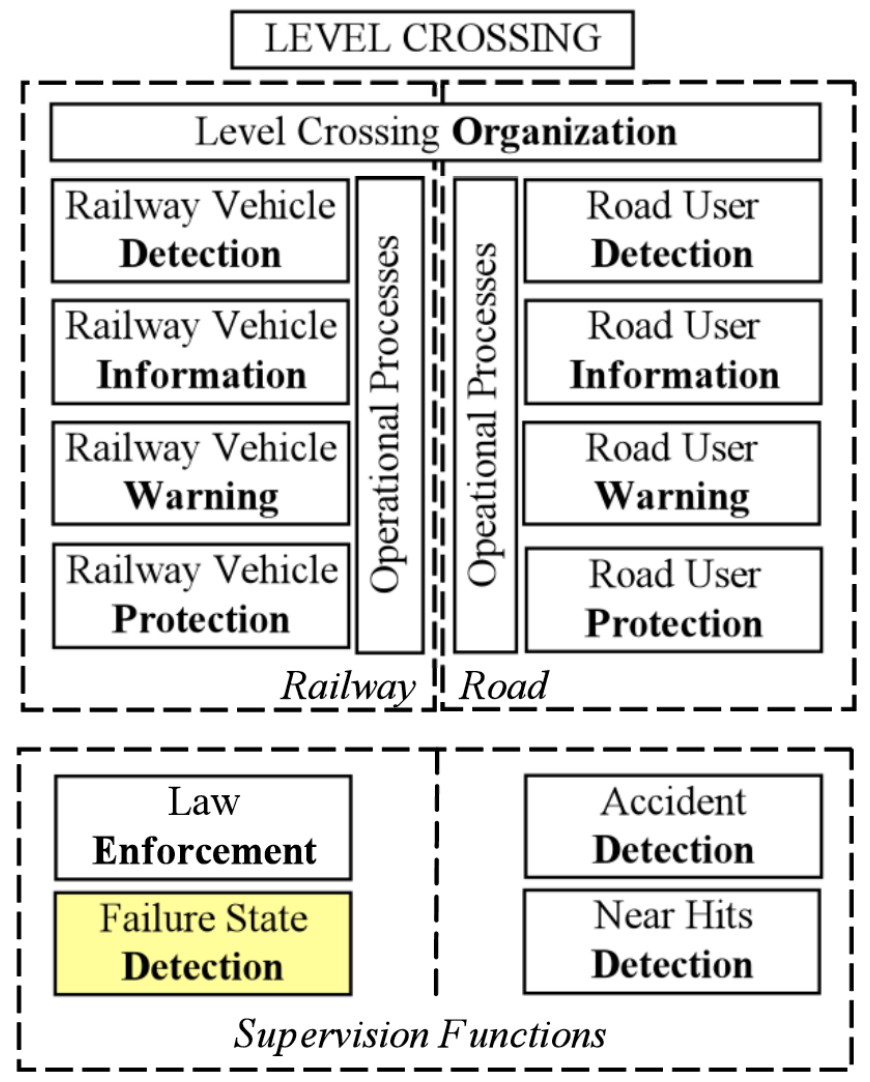

Fig. (3). Function decomposition.

Correct operation of all components of LC can guarantee desired safety level for road and railway traffic participants. As neither any malfunction can endanger any person even cause any harm to property or devices, safety techniques have to be implemented to recognize failures and bring the system into safe state in such cases. However, any fault means the disturbance of primary safety [13] and enlarges the risk, as the influence of human factor on overall safety is much more significant in case system not being functional as shown at Fig. (4).

The fault state of LC interlocking system is at systems used in Slovak Republic signalled for road traffic participants by no signal shining [14]. No matter if interlocking system is equipped with "active signalling" flashing white light or not, many drivers rely on warning being inactive signals no railway vehicle entering dangerous zone of LC. That is why keeping availability of LC interlocking system and its recovery as soon as possible is of big importance.

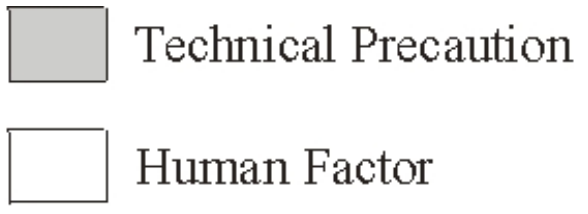

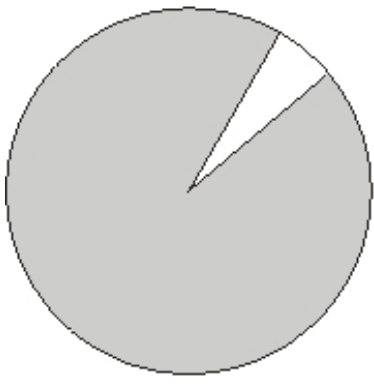

a)

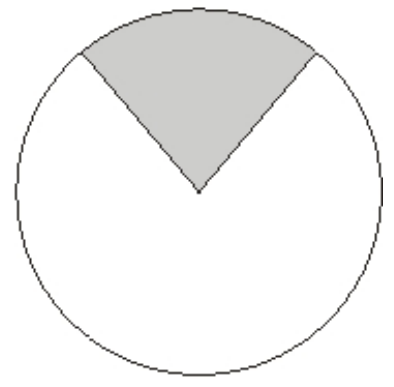

b)
Fig. (4). Proportion of technical precaution and human factor on safety if system is a) functional b) non-functional.

\subsection{Computer-Based Diagnostics}

Fault diagnosis is one of four procedures associated with process monitoring displayed at Fig. (5), consisting namely of fault detection, fault identification, fault diagnosis and process recovery [15].

According to [15] fault detection can be divided to detection of anomalies, diagnosis (identification of anomalies) and prognoses (warning of threat anticipated). Considering fault-tolerant systems after failure detected, the system can be even reconfigured [17].

Every railway signalling system has to dispose unconditionally of fault detection in order to be able to recognize its own failure, to negate failure occurrence and to bring itself to a safe state. Fault identification and diagnostics are then needed so as to bring the system back to its original functionality.

Building a diagnostic system [11] it should be considered, that this system should have efficient

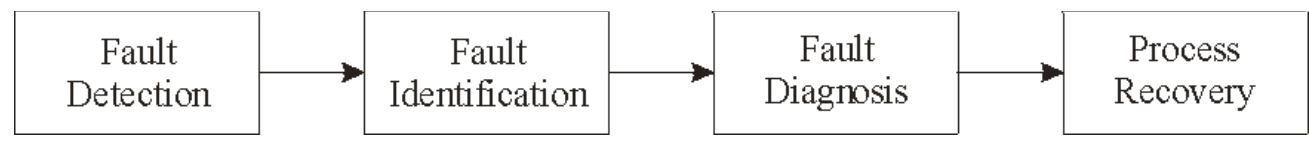

Fig. (5). Monitoring process. 
construction, reasonable maintainability, adequate coverage, bring correct answers, demand minimum effort from the user, bring solutions in appropriate time and prove good costs/benefit ratio.

\subsubsection{Diagnostic Approaches}

General approaches used in diagnostics can be classified as data-driven, analytical and knowledge based. Data-driven methods are derived directly from process data, analytical approach uses mathematical models constructed from first principles [15]. Both methods are suitable especially for systems equipped with lots of sensors offering huge amount of process variables values. Most of LC safety systems use modular structure where individual modules are responsible for handling elements in trackside itself, or operate on control level. Inputs for diagnostic process should then be events in system detected by observing communication on busses, rather than concrete values of measured quantities. These data are inadequate to apply a data-driven method, but qualitative or semi-qualitative models can be derived from causal modelling of the system, expert knowledge, or fault symptom examples. That is why knowledge based methods are especially suited to diagnostics of these systems.

\subsubsection{Diagnostic Fault Trees}

Diagnostic fault trees represent one of the main ways how to express diagnostic strategy. They are easy to be understood, are used to describe troubleshooting procedures being good way to share knowledge between the constructor of the diagnostic system and diagnosticians and can represent wide range of diagnostic problems.

There are also several problems building fault trees. The diagnostic fault tree can get very large and difficult to maintain, there is a problem building a new fault tree if there is no previous experience of diagnosing the device, every change in system structure to fit it to needed conditions demands a new version of the fault tree, different problems in the same system such as problems with SW, HW or network can be represented through separate trees which are then difficult to relate and it is not appropriate if continuous diagnosis is needed.

\subsubsection{Case-Based Diagnostic Systems}

Case-based reasoning is applicable to many types of problem solving. It can fasten broad but shadow domain, where number of loosely connected problems demanding different kinds of expertise has to be dealt with, primary source of knowledge is experience rather than theory and gained solutions are reusable.

The solution is then gained in next steps:

- $\quad$ Obtain symptoms of the diagnostic problem;

- Match symptoms with description of previous problems (cases);

- $\quad$ Produce a new solution and evaluate it;

- If the new problem was different from any known problem, it should be added to case-base.

\subsubsection{Model-Based Diagnostic Systems}

The idea is that model should predict behaviour of observed system. It is needed to decide what kind of model is appropriate (simple dependences, state-based, componentbased models with or without faults simulation), what aspects should be modelled (models of physical structure and behaviour, logical structure and behaviour, process, causal models; granularity of simulation should be considered) and what kind of framework should be build (quantitative or qualitative).

Ideally diagnostic models should reflect the structure of the system, should be reusable, accessible, understandable and easily obtainable.

\subsubsection{Real-Time Diagnosis}

In some cases it is needed that the system should be monitored continuously, changes in monitoring conditions should be taken into account, and action should be initiated automatically.

Among several ways of building real-time monitoring and problem detection systems fall building monitors by hand, quantitative modelling, qualitative model-based problem detection or neural networks.

\subsubsection{Sources of Diagnostic Information}

When designing diagnostic system, it is important to utilise available information about monitored system, its behaviour and processes running in it. Information being at disposal:

- $\quad$ Records of previous problems on the system;

- Component reliability information;

- Design information from risk analysis and proving the safety:

- $\quad$ Fault tree analysis (FTA)

- $\quad$ Failure mode and effects analysis (FMEA)

- Hazard and operability report (HAZOP)

- Informal description of system working, instructions for maintenance.

As far as LC safety system is concerned, it can be supposed, that according to using high reliability elements/blocks promptly reacting to any failures, there is not a huge amount of previous problems recorded, but on the other hand safety analysis reports can be expected being at disposal.

\subsection{Knowledge-based Approach to Diagnostics}

Knowledge-based systems are assigned several advantages in comparison to conventional programming [11]:

- $\quad$ They offer extra functions such as ability to explain why the question is being asked, allowance to retract answers, ability to clarify what does the question mean, explain how the solution was derived, etc.;

- $\quad$ Avoid asking unnecessary questions so they do not ask for information that were already given or those, that are not needed for inference or irrelevant when considering given facts;

- Most of shells bring better quality of graphical user interface, for which it is not needed to write extra code. 
Generally there are several knowledge based approaches including pattern recognition, probabilistic approach, and expert systems $[15,18]$.

\subsubsection{Pattern Recognition}

Considering, as mentioned, that railway signalling systems are well mapped, structure of them is unambiguous, and working processes as well as failure processes are known and defined, pattern recognition approaches such as neural networks $(\mathrm{NN})$ or self-organizing maps are not taken for appropriate.

Structure of the network cannot be adapted to structure of the system; nodes in inner layers do not correspond to any state of the system in the same manner as they are not representing any component or attribute of the system.

Problem is also, that creation of NN similarly as its training demands huge amount of training data on the basis of which the relations between input diagnostic data and output solutions can be created and weights in neuron transfer (activating) functions set. Such statistics are especially for LC systems characteristic in low fault events rate hardly available.

\subsubsection{Probabilistic Approach}

Probabilistic approach derives the solution using Bayesian theorem on the basis of events occurred in system being known as well as relations among possible event occurrences conditioning final fail-state. Since all states into which the fail-safe system is able to get have to be considered, this information can be advantageously utilised.

Bayesian network (BN) as the main representative of this approach has advantage in ability to deal with complex and uncertain problem at the same time. It models the real world qualitatively defining single events and relations among them, and also qualitatively assigning probabilities of event occurrences to unconditional nodes and conditional probability tables (CPT) to conditioned nodes.

On the other hand great disadvantage of $\mathrm{BN}$ is huge amount of probabilities needed to be assigned. It is especially difficult to determine all the conditional probabilities for CPT of successor nodes catering for influence of all parent nodes events occurrences and their combinations. Either extensive statistics are necessary, or these values have to be set just according to expert assessment.

Trying to use available data, BN is suitable particularly if FTA of the system is at disposal. Following algorithm can be then used to convert fault tree (FT) into BN [12]:

1. Creation of BN root nodes for every FT leaf

2. Creation of BN conditional nodes matching FT gates

3. Connecting of $\mathrm{BN}$ nodes through oriented edges according to connections of gates in FT

4. Assigning of probabilities to $\mathrm{BN}$ root nodes on the basis of FT leaf events occurrence

5. Creation of CPT for BN successor nodes corresponding to appropriate kind of FT gate
In this case probabilities of root nodes can be determined according to failure rates of single components of the LC system, while conditional probabilities correspond to logical functions of a certain gate [19]. In order to cater for uncertainty and impact of unknown events or events not being considered, it is possible to define these nodes as "noisy" (if the function of the given gate permits that there is one event entering the gate that can by itself alone cause activation/deactivation of the gate, its "noisy" equivalent reflects, that this one does not have to definitely imply truthfulness/falsity of consequence) or "leaky" (allow to concede, that some background probability exists that the system can provide malfunction also if all components of the system are working properly).

\subsubsection{Expert Systems}

Expert systems generally allow making logical inferences using available expert knowledge and giving decisions with reasoning on the basis of these.

Such a system is modelling rather the way the human expert is thinking and making decisions, than modelling the real world and its relations. This allows also information expressed in natural language being processed and transformed into knowledge, and so all the informal descriptions of the system, manuals, instructions for maintenance, etc. being considered and handled as sources of knowledge.

The knowledge can be represented using various formalisms including predicate logic, production rules, semantic networks or frames. Especially production rules are about a great popularity thanks to its simplicity and clearness. Causal-consequent relations between failure and its consequences can be simply modelled via IF-THEN rules, which can be in order to handle uncertainty supplemented with certainty factors and measures of belief expressing uncertainty, which the evidence has been observed with, as well as how strong does the expert believe in validity of the rule itself.

If there is well structured description of system failures and their consequences such as tables and reports of FMEA, its cause-consequence representation can be taken advantage of and it can be easily converted to IF-THEN production rules.

The system can sufficiently get over lack of information and give list of possible fault causes taking priority of offered solutions into account.

\section{METHODOLOGY DESIGN}

Designing knowledge-based diagnostic system, appropriate inference mechanism is needed to be chosen taking the form of available data into consideration, so that information about object of diagnostics can be transformed into knowledge which inference mechanism is able to decide on the basis of, and so that diagnostic data from the process being diagnosed can be processed as input data for the inference. Basic methodology is shown at Fig. (6).

There are several ways, how to obtain desired information about the system, and thus several forms which this information can be expressed through. 
In the life cycle of the system there is a lot of documentation produced in every single stage, which can stand for source of information. Unfortunately most of this documentation is kept in natural language form that is ordinarily difficult to formalize and knowledge engineer assistance is necessary for knowledge being discovered in this data.

Safety related systems such as LC safety systems in contrast to conventional control systems have to be put during their design stages through risk analysis, and the safety of the system has to be established before putting the system into operation. As the product of such analysing and proving, various formal or informal specifications and models of system structure and behaviour arise, including treating failures processes, consequences and system reacting to failures in detail.

On the other hand useful information can be gained from operation and maintenance of the system. When considering data relevant to failures at fail-safe systems, it is hardly feasible to gain comprehensive statistics and data in required range can be hardly acquired, due to high mean times to failure and low failure rates of components used.

In case informal data is at disposal, it is needed to select target data out of it and to carry out formalisation subsequently.
If data structured enough is at disposal, it is possible to apply some transformation algorithm to convert it into knowledge.

In case statistical data is available, some kind of machine learning or automated knowledge discovery method can be used to obtain data required.

As for providing of facts, it is needed to gain required data from the process running and to transform this to desired formalism so that inference mechanism can use it for making decisions. If using computer-based diagnosis based on watching communication on system busses, diagnosis relevant messages should be recognized and separated, and their meaning provided to inference mechanism in the proper form. Using BN it means relevant node validity should be set according to events observed in the process; using production rules facts formulation correspond to how evidence of single rules is formulated, etc.

\subsection{Knowledge-Based Diagnostic System Architecture}

The fundamental knowledge-based system architecture consists of inference mechanism responsible for making logical inferences and decisions with reasoning, knowledge base accumulating available knowledge and working memory (base of facts) reflecting actual state of the process.

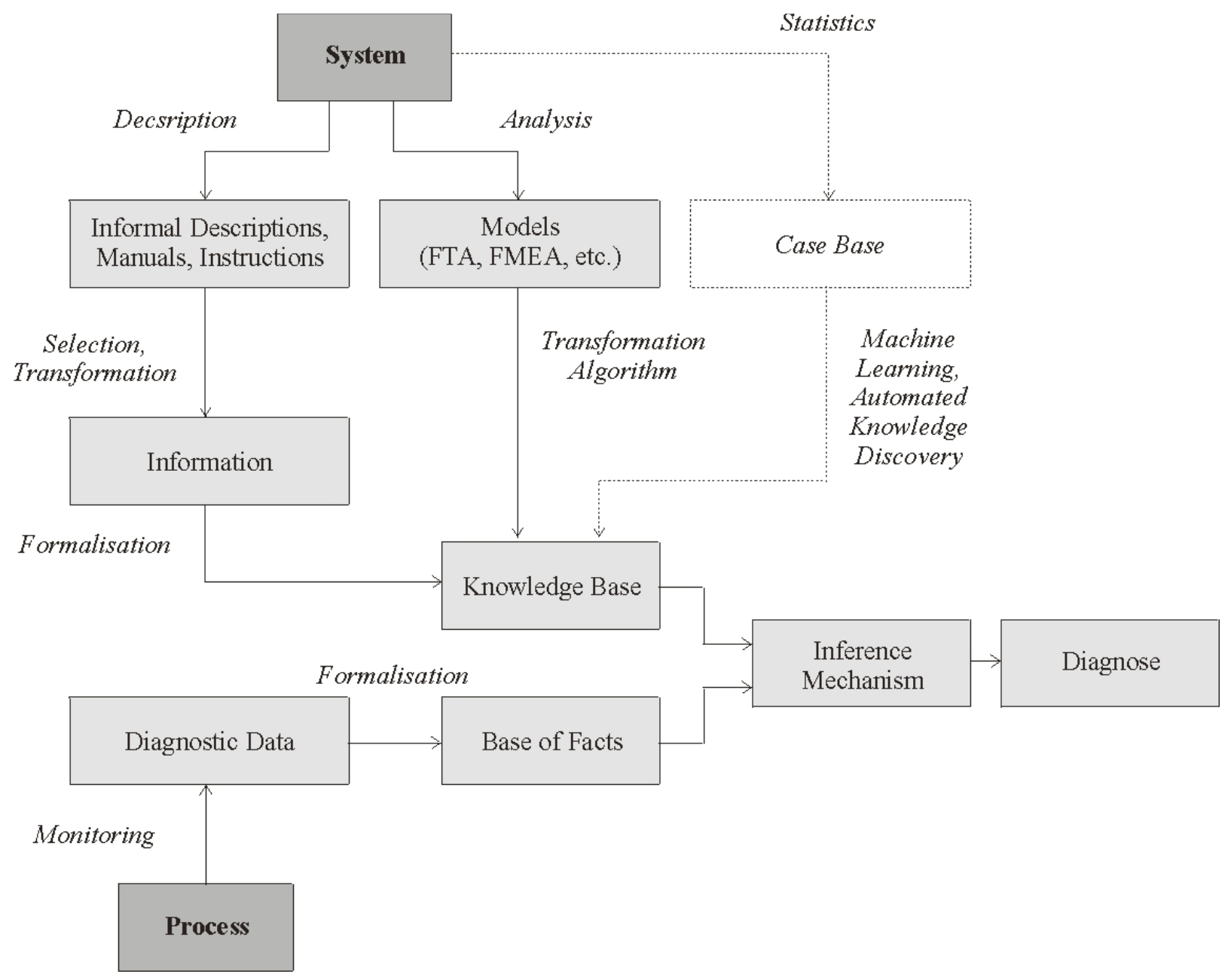

Fig. (6). Methodology design. 
To acquire diagnostic data from the process being diagnosed, to communicate with the user and generally to process the requirements of inference engine, service application should be built above the knowledge-based core of the system. Whole architecture is depicted at Fig. (7).

Core of the system is supposed to be made out of some expert system shell filled with appropriate knowledge. Service application is assumed to be written in conventional programming language.

Information acquisition should deal with acquiring of relevant information about process such as observing communication flows, reading databases, etc., and providing this information to management of facts.

Management of facts task is to bring available facts to required formalism and to store it in working memory; that means to call appropriate shell API function if available, or directly write the fact to the file, respectively change some value in the file.

Communication interface ensures communication with users. It offers solutions to user, ask user for complementary facts if needed, and process user requests.

Action execution task is to process solutions established by inference and answer its requests. In case request to supplement the working memory is demanded, information acquisition should be preferred to ask for looking for necessary information in available data (search databases, check process), just subsequently ask user.

The goal of an explanation subsystem is to give explanation why certain data is required, how the inference was provided, and why given solution was determined. It is of special meaning particularly in case that actual problem solving differs in some way from solution given by the knowledge-based system and relations in knowledge base which have lead to that solution should be checked and repaired.

Whole the structure can be supplemented with a validation mechanism. This mechanism provides access to knowledge base and enables its recondition in case there were some inaccuracies discovered. Every solution established by inference mechanism should be provided except to user also to validation mechanism and after recovery of system compared to actual solution, so that in case of any discrepancy detected used knowledge can be checked and knowledge base can be adjusted.

\subsection{Dealing with Various Kinds of Knowledge}

LC safety system is a complex system that can be decomposed in several layers in horizontal or in vertical direction. It is probable, that descriptions and analysis of system are made for single components or related to certain layers of decomposition. For example specification of overall control of the system is surely made in other way using other tools than descriptions and analysis of elements in trackside. As mentioned above various sources of information are suitable for being processed using different knowledge-based approach. It may be more suitable to build $\mathrm{BN}$ for elements in trackside on the contrary to possible suitability of production rules definition for communication on control level. This can lead to several knowledge-bases being created, which associations can be just hardly searched in, also if same approach used for their creation (e.g. BNs of two elements in trackside).

Two architectures were taken into account when dealing this task.

In first case standard table architecture displayed at Fig. (8) was considered. All the inference mechanisms are sharing the same space for storing facts, so that all

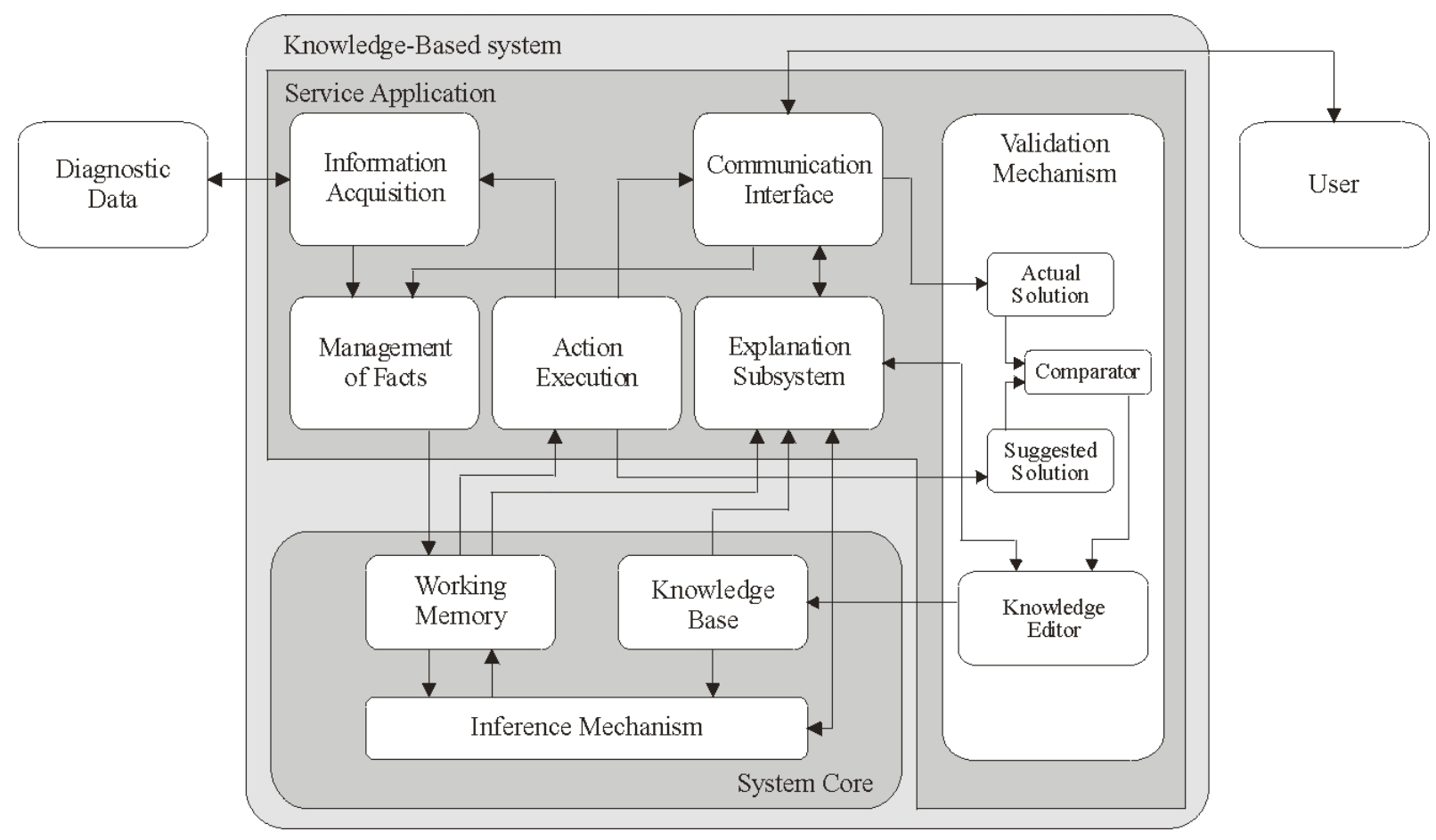

Fig. (7). System architecture. 


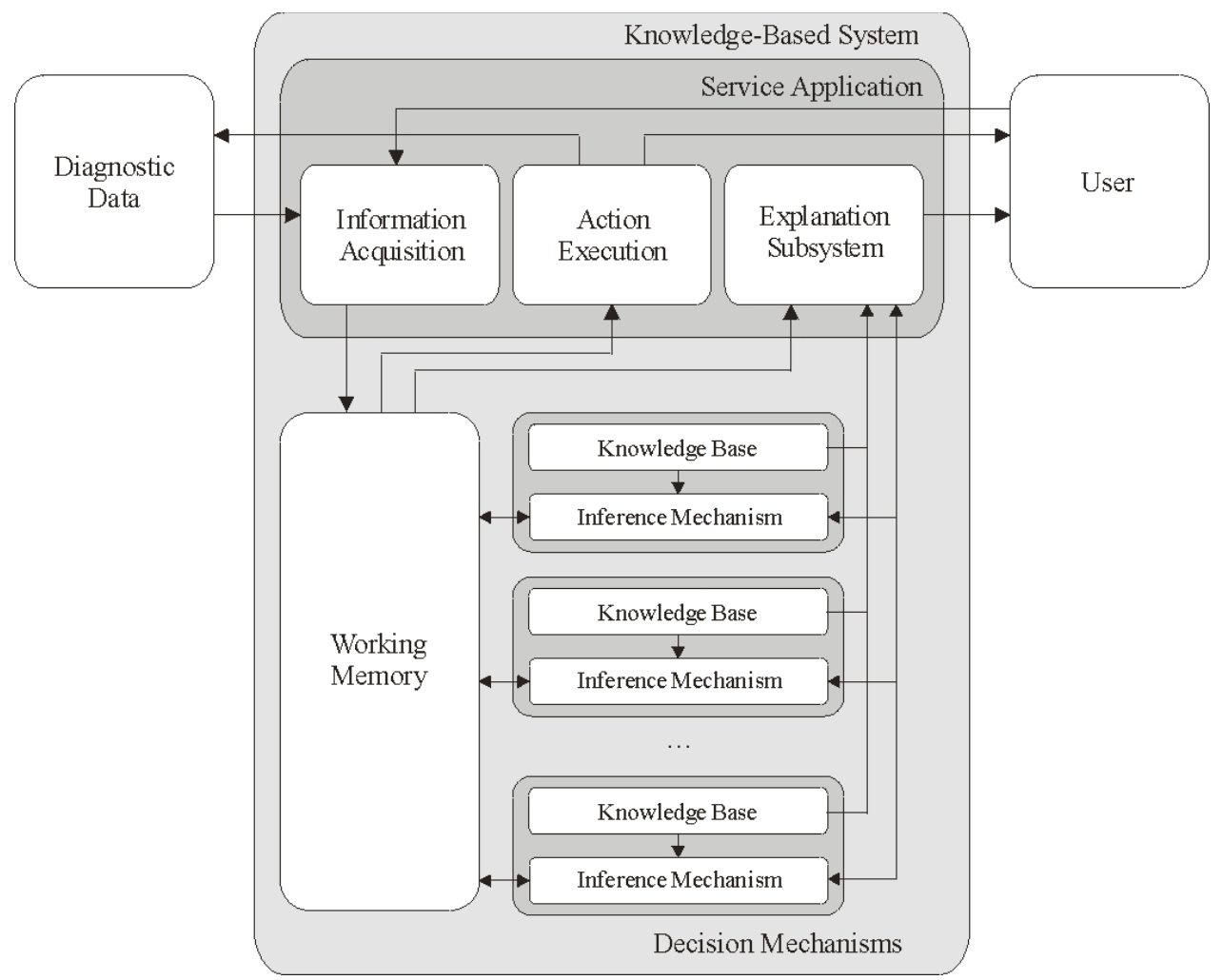

Fig. (8). Extended architecture using various decision mechanisms sharing working memory.

information is anytime accessible to any of them so as any fact inferred by one of inference mechanisms is immediately at disposal for all the other mechanisms. Working memory has to dispose of facts management in this case so that it is able to provide demanded facts in proper form for demanding mechanism and convert facts from one formalism to another.

In second case shown at Fig. (9) it is supposed, that working memory is separated according to relevance of facts

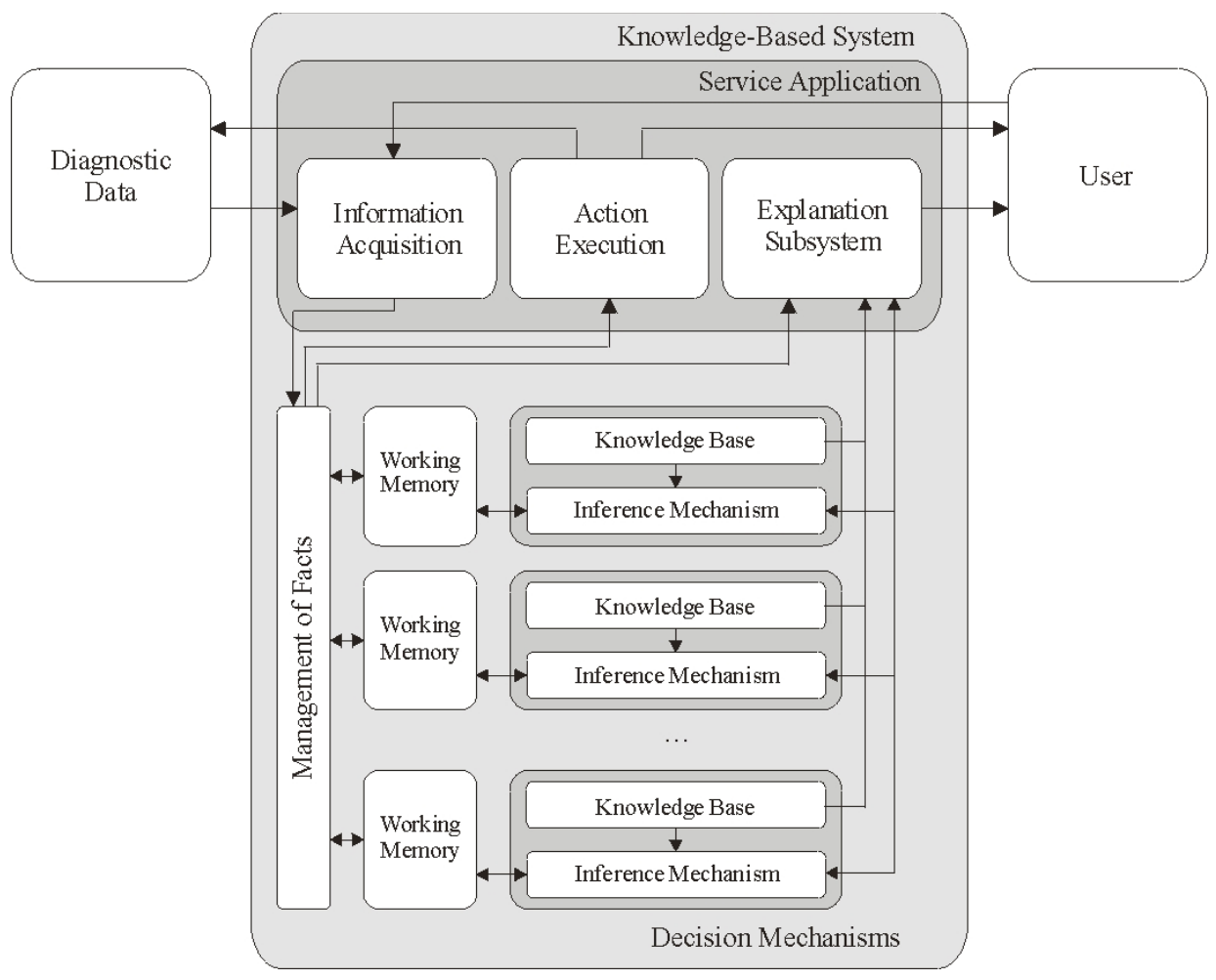

Fig. (9). Extended architecture using various decision mechanisms with separated working memory. 
to individual knowledge-bases. On one hand irrelevant facts are avoided being considered, on the other hand facts with relevancy for more inference mechanisms are stored multiple. There should work management of facts above all facts-bases, which consider which facts are relevant for which inference mechanism.

\section{CONCLUSIONS}

Authors have concentrated on characteristics of present conditions at Slovak LCs, their particularities have been pointed out, and statistical data hasb been presented so as structure of this data, its versions and trends. Main attention has been paid to knowledge-based approach to diagnostics of computer LC safety systems. The paper results in summary of ways of problem dealing. As outcome the methodology for such a diagnostic system has been introduced and possible system architectures outlined. The next direction of research work in this area should lead to implementation of proposed methods into application for diagnostics of real LC system BUES 2000 [20]. The diagnostic system actually running upon BUES 2000 is able to read communication on control level and to store corresponding part of this communication in case unexpected behaviour is detected. Human expert is then needed to analyse the data and to identify and localise the failure. Diagnostic data is available in the form of telegrams having structure "yyyy $\mathrm{xx} \mathrm{xx} \mathrm{xx} \mathrm{xx}$ $\mathrm{xx} \mathrm{mm}$ ss hh", where " $\mathrm{y}$ " stands for identification of a sender, " $x$ " for information part of telegram and "mmsshh" for time of dispatch.

\section{ACKNOWLEDGEMENTS}

This paper was written with motivation to take up again the work performed within the $6^{\text {th }}$ FP project SELCAT and to present the concept of present and future work performed within the Ph.D. study of the $2^{\text {nd }}$ author dealing with usage of the knowledge-based approach to diagnostics of computerbased LC safety installations. This work was supported by the grant assigned to the project VEGA 1/0040/08 "Mathematic-graphical modelling of safety attributes of safety-critical control systems".

\section{REFERENCES}

[1] EU energy and transport in figures, Office for the Official Publications of the European communities, Luxembourg, 2009.

[2] Railways of the Slovak Republic (Železnice Slovenskej republiky), Annual Report 2008, GR ZSR, 2009.
[3] SELCAT - "Safer European Level Crossing Appraisal and Technology", web portal. Available from: http://www/levelcrossing.net, [access date, June 2006].

[4] Railways of the Slovak Republic (Železnice Slovenskej republiky), D17 - Regulation for reporting and inspection of accident events and abnormalities in railway operation (2nd edition), ŽSR, 2004.

[5] European Railway Agency (ERA), A Summary of 2004-2005 EU Statistics on Railway Safety, 2006

[6] J. Zahradník, K. Rástočný and A. Janota, "Assurance of Road Traffic Safety at Level Crossings of ŽSR under failure of LC System", In the $2^{\text {nd }}$ Workshop by Safer European Level Crossing Appraisal and Technology Proceedings, Marakech, pp. 179-189, 2007.

[7] Slovak Standards Institute (SÚTN), STN P 34 2651: Železničné priecestné zariadenia (Railway Level Crossing Installations), SÚTN, 1999.

[8] Zákon č. 315/96 Z.z. o premávke na pozemných komunikáciách a s ním súvisiace vyhlášky a predpisy (The Law No.315/96 Z.z. about operation at the surface communications and related regulations and rules), The Slovak Republic, 1996.

[9] Railways of the Slovak Republic (Železnice Slovenskej republiky), Ž1:Pravidlá železničnej prevádzky (Ž1: Railway traffic rules), ŽSR, 2005

[10] R. Slovák, A. G. Schielke and E. Schnieder, "Level Crossing Safety Performance Monitoring by Web based Knowledge Management System", In the $10^{\text {th }}$ World Level Crossing Symposium, Safety and Trespass Prevention Proceedings, Paris, pp. 19-32, 2008.

[11] Ch. Price, Computer-Based Diagnostic Systems. Computer-Based Troubleshooting, Springer-Verlag, 1999.

[12] A. Bobbio, L. Portinale, M. Minichino and E. Ciancamerla, "Improving the Analysis of Dependable Systems by Mapping Fault Trees into Bayesian Networks", Reliability Engineering and System Safety, vol. 71, pp. 249-260, 2001.

[13] J. Zahradník, K. Rástočný and M. Kunhart, Bezpečnost' železničných zabezpečovacich systémov (Safety of Railway Interlocking Systems), EDIS, 2004.

[14] J. Zahradník, K. Rástočný, Aplikácie zabezpečovacich systémov (Applications of Interlocking Systems), EDIS, 2006.

[15] L. H. Chiang, E. L. Russel and R. D. Braatz, Fault Detection and Diagnosis in Industrial Systems, Springer-Verlag, 2001.

[16] P. Kulczycki, "Statistical Kernel Estimators for Design of a Fault Detection, Diagnosis, and Prognosis System", The Open Cybernetics and Systemics Journal, vol. 2, pp. 180-184, 2008.

[17] D. Krokavec and A. Filasová, "Reconfiguration Flexibility Offered by Output State Feedback in Fault-Tolerant Control system", In the $4^{\text {th }}$ Slovakian - Hungarian Joint Symposium on Applied Machine Intelligence Proceedings, Herl'any, 2006.

[18] E. Castillo, J. M. Gutiérrez and A. S. Hadi, Expert Systems and Probabilistic Network Models, Springer-Verlag, 1997.

[19] J. Spalek, A. Janota, M. Balažovičová and P. Přibyl, Rozhodovanie a riadenie spodporou umelej inteligencie (Decisioning and Control with AI Support), EDIS, 2005.

[20] Scheidt \& Bachmann GmbH, "BUES 2000 Dokumentation, Systembeschreibung für Instandhalter", Scheidt \& Bachmann, 2002. 